\title{
СОВРЕМЕННАЯ ПРОМЫШЛЕННАЯ ПОЛИТИКА РЕГИОНОВ РОССИИ: ПРОБЛЕМЫ ТЕОРИИ, МЕТОДИКИ И ПРАКТИКИ
}

\author{
(C) 2018 Карлик Александр Евсеевич \\ доктор экономических наук, профессор \\ зав. кафедрой экономики и управления предприятиями и производственными комплексами \\ Санкт-Петербургский государственный экономический университет \\ Россия, 191023, Санкт-Петербург, ул. Садовая, д. 21 \\ E-mail:karlik1@mail.ru \\ (c) 2018 Гринюк Кирилл Петрович \\ доцент кафедры финансов и экономической безопасности \\ Курганский государственный университет \\ Россия, 640020, г. Курган, ул. Советская, 63 \\ E-mail: grinkirill@yandex.ru
}

В статье предложено авторское определение промышленной политики, сформулированы её принципы и задачи. Установлено несоответствие государственных документов, принимаемых в регионах России в целях развития промышленности, требованиям, предъявляемым к промышленной политике. На этой основе выявлены причины низкой эффективности существующей промышленной политики российских регионов.

Ключевые слова: промышленная политика, промышленный комплекс, технологический уклад, управляющий субъект.

Промышленная политика российских регионов на современном этапе характеризуется отсутствием единого подхода к её разработке и методам реализации. Несмотря на унификацию ряда мер поддержки промышленности, обеспечиваемую федеральными нормативными актами (например, создание региональных фондов развития промышленности, специальные инвестиционные контракты), российские регионы самостоятельны в выборе подходов к формированию промышленного комплекса, являющихся основным элементом промышленной политики. Зачастую такая «самостоятельность» приводит к низкой эффективности реализуемых регионами промышленных политик. Одной из основных причин этого является отсутствие достаточного теоретико-методического обеспечения процессов разработки промышленной политики и формирования промышленного комплекса.

Обращение к литературным источникам $[8,9$, $14,16,17,18]$ показывает отсутствие единого подхода к пониманию термина «промышленная политика» и приводит к необходимости уточнения данного понятия.

Под промышленной политикой предлагается понимать систему государственных мер по организации производства промышленных продуктов заданного технологического уклада посредством формирования соответствующего этому укладу промышленного комплекса. Cогласно этому определению, сущность промышленной политики заключается в том, что она есть функция технологического уклада (ТУ). Отличие предлагаемого определения от имеющихся в литературе заключается в привязке промышленной политики к технологиям, посредством которых производится промышленный продукт. По этой причине предложенное определение представляется более универсальным и практически применимым, поскольку устанавливает зависимость системы мер промышленной политики от технологий (ТУ), с помощью которых должен производиться промышленный продукт, задаваемый в качестве цели промышленной политики.

При разработке промышленной политики региона целесообразно учитывать два основополагающих и взаимосвязанных принципа:

1. Принцип необходимости предполагает учёт объективных тенденций научно-технологического развития, складывающихся в производстве промышленной продукции, что продиктовано требованием обеспечения конкурентоспособности промышленного комплекса. 
2. Принцип возможности предполагает установление того, могут ли и в какой степени внутренние (собственные) ресурсы региона обеспечить развитие на территории региона господствующих технологий определенного ТУ.

Промышленная политика также должна решать 3 задачи (рисунок 1):

1. Определение цели промышленной политики, т.е. фактически того ТУ, продукт которого необходимо произвести. Это центральный элемент любой политики, определяющий как все последующие действия, так и ожидаемый результат.

2. Определение управляющего субъекта. Таким субъектом является государство, однако, степень его участия может быть разной и определяется она этапом развития ТУ. При освоении новых технологий и становлении новых ТУ государство активизирует своё участие в вопросах формирования новых производств. После завершения освоения и перехода в фазу зрелости очередного ТУ государство постепенно отходит от широкой поддержки производства и передаёт управление производством частным экономическим субъектам, сохраняя контроль за ними.

3. Определение системы мер (методов реализации) промышленной политики.
Принципиальным является соответствие методов заявленной цели (т.е. ТУ, производство продукции которого организуется).

То обстоятельство, что для организации производства продуктов разных ТУ требуется разная система мер промышленной политики, обусловлено тем, что для каждого ТУ характерен свой состав, структура и система связей промышленного комплекса, в рамках которого организуется замкнутый цикл производства этих продуктов. Поэтому для организации производства продукции разных ТУ необходимы разные меры по формированию разного состава, разной структуры и разной системы связей промышленного комплекса.

Анализ региональных промышленных политик, выполненный на примере регионов Уральского федерального округа, показывает, что современные промышленные политики регионов не соответствуют указанным выше требованиям, предъявляемым к промышленной политике (не содержат её элементов).

В Курганской области с 1999 года действует Закон «Об основах промышленной политики Курганской области» [5] и регулярно принимаются соответствующие документы: «Концепция промышленной политики» (на 2000-2005 гг.

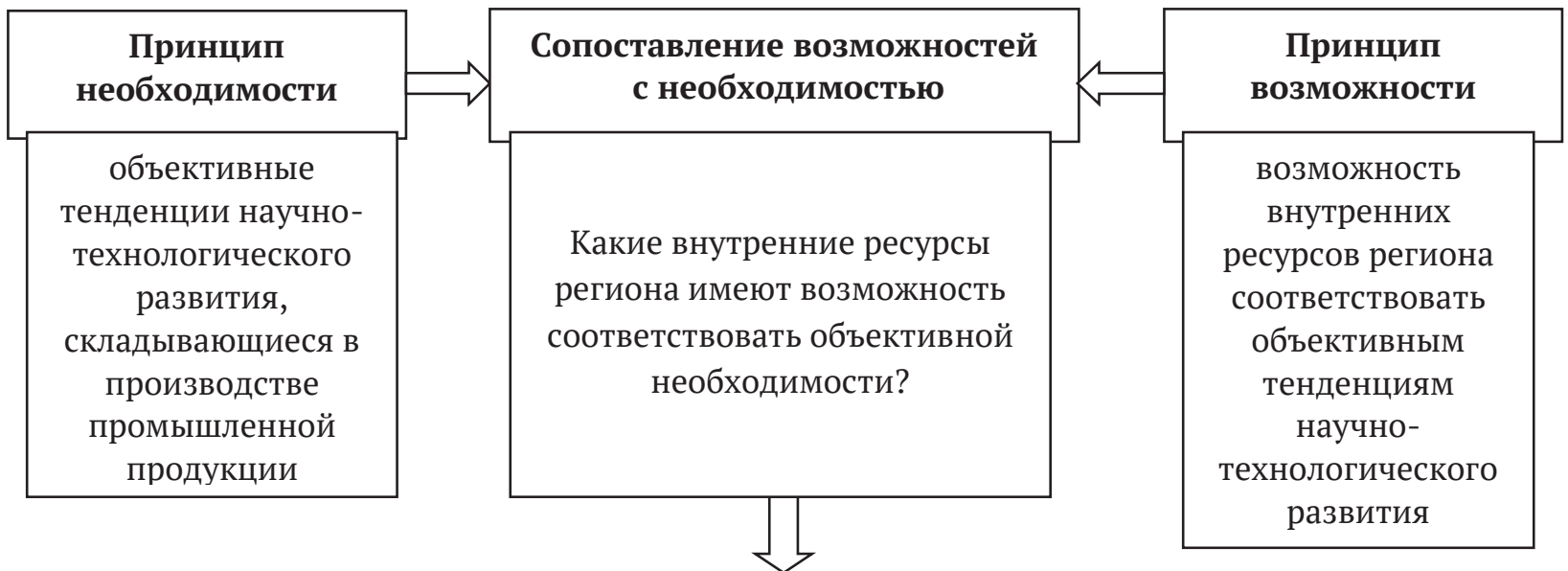

Разработка промышленной политики посредством решения трёх задач:

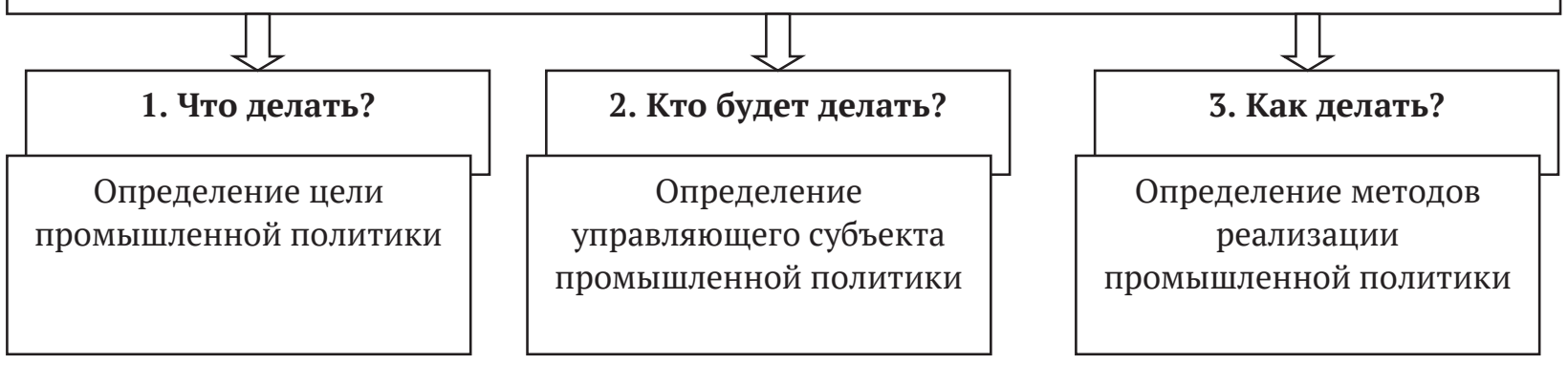

Puc. 1. Логическая схема разработки промышленной политики 
[11] и на 2006-2010 гг. [12]), Целевая программа «Развитие промышленного комплекса на 20112015 гг.» [19] и Государственная программа «Развитие промышленного комплекса и повышение его конкурентоспособности на 2014-2018 гг.» [1].

Цель Государственной программы «Развитие промышленного комплекса и повышение его конкурентоспособности на 2014-2018 гг.» содержит общую формулировку - «формирование современного высокотехнологичного промышленного комплекса Курганской области, поставляющего на рынок товаров и услуг конкурентоспособную востребованную продукцию». Формально она соответствует глобальным тенденциям научно-технологического развития, т.к. на современном этапе развития высокотехнологичной может быть только продукция не ниже 5-го ТУ. Но данная цель не содержит конкретизации, какую именно «высокотехнологичную, конкурентоспособную и востребованную» продукцию производить, какими технологиями.

Управляющий субъект. В концепциях и программах отсутствует представление о государстве как об управляющем субъекте, несмотря на то, что 5-й (и тем более 6-ой) ТУ для Курганской области является новым. Так, средства государства на финансирование мероприятий в сфере промышленности до 2010 г. не предусматривались, в программе на 2011-2015 гг. предусмотрены лишь в сумме 3,25 млн. руб. (0,02\% от общей суммы программы), в программе на 2014-2018 гг.- 6,4 млн. руб. (0,06\% от общего объема предусмотренных средств).

В этом заключается противоречие указанных государственных документов: с одной стороны, их цель фактически предусматривает становление промышленного комплекса 5-6 ТУ, с другой стороны участие государства в этом процессе в качестве управляющего субъекта (критически важное как раз на стадии становления нового ТУ) не предусмотрено. Таким управляющим субъектом в концепциях и программах представлен частный бизнес, который может являться таковым лишь на стадии зрелости ТУ.

Система мер. Отсутствие конкретизации цели предопределяет отсутствие системы мер по её достижению, т.е. системы мер по формированию промышленного комплекса конкретного ТУ.

Указанные документы содержат лишь направления деятельности Правительства Курганской области: такие как, «активная позиция в вопросах сохранения и развития промышленного потенциала», «поддержка эффективного собственника и содействие формированию и расширению спроса на продукцию», «проведение совещаний, конкурсов, выставок», «мониторинг деятельности производственных субъектов», «выпуск в радио- и телеэфир передач о промышленности», не выходящие за рамки «кабинетной работы».

Анализ имеющихся документов в сфере развития промышленности Курганской области позволяет сделать вывод об отсутствии в регионе промышленной политики, т.к. при формальном наличии только цели (сформулированной в общем виде и лишь косвенно указывающей на необходимость перехода к производству технологиями 5-го и 6-го ТУ), представления об управляющем субъекте и системе мер отсутствуют (табл. 1).

В Свердловской области промышленная политика реализуется на основе:

- Закона «Об отдельных вопросах реализации в Свердловской области промышленной политики Российской Федерации» [6];

- Концепции областной целевой программы «Развитие промышленности Свердловской области и повышение ее конкурентоспособности» на 2014-2018 годы [10];

- Государственной программы «Развитие промышленности и науки на территории Свердловской области до 2020 года», (далее - Государственная программа) [2].

Таблица 1. Характеристика промышленной политики Курганской области

\begin{tabular}{|l|l|l|l|l|}
\hline \multirow{2}{*}{$\begin{array}{c}\text { Период } \\
\text { времени }\end{array}$} & \multicolumn{1}{|c|}{ Цель } & $\begin{array}{c}\text { Элементы промышленной политики } \\
\text { Упавляющий } \\
\text { субъект }\end{array}$ & $\begin{array}{c}\text { Система мер по фор- } \\
\text { мированию промыш- } \\
\text { ленного комплекса }\end{array}$ & \multirow{2}{*}{ Вывод } \\
\hline \multirow{2}{*}{$\begin{array}{l}2000 \text { г.- по } \\
\text { наст. время }\end{array}$} & $\begin{array}{l}\text { - заявлена; } \\
\text { тенденциям научно-технологи- } \\
\text { ческого развития; } \\
\text { - не конкретизирована (прио- } \\
\text { ритеты не сформулированы). }\end{array}$ & $\begin{array}{l}\text { Не соответствует } \\
\text { заявленной цели }\end{array}$ & $\begin{array}{l}\text { Не соответствует } \\
\text { заявленной цели }\end{array}$ & $\begin{array}{l}\text { Промышлен- } \\
\text { ная политика } \\
\text { отсутствует }\end{array}$ \\
\hline
\end{tabular}


Цель. Несмотря на отсутствие в цели указания на производство продукции конкретного ТУ, исходя из содержащихся в ней формулировках «на основе интеграции в мировую технологическую среду и разработке передовых промышленных технологий» - можно сделать вывод, что фактической целью является переход к производству продукции 5-го и 6-го ТУ, т.к. «передовыми промышленными» в настоящее время являются технологии и продукты данных ТУ. Кроме этого Государственная программа содержит ряд приоритетов в сфере промышленности, что позволяет также сделать вывод о конкретизации заявленной цели в разрезе производств.

Управляющий субъект. В Государственной программе отсутствует представление о государстве как об управляющем субъекте, несмотря на то, что 5-й (и тем более 6-ой) ТУ в данном регионе находится в стадии становления. В структуре финансирования Государственной программы преобладают внебюджетные источники: 20,4 млрд. руб. (73,6\%). Фактически управляющим субъектом объявлен частный бизнес. Однако, частный бизнес может стать управляющим субъектом процессов формирования промышленного комплекса в рамках 4-го ТУ, т.к. он находится в Свердловской области в стадии зрелости, но не в рамках 5-го или 6-го ТУ. Это означает, что в качестве управляющего субъекта предусмотрен субъект для другого, чем предусмотренного в качестве цели, ТУ: для 4-го. В этом состоит противоречие Государственной программы.

Система мер. Государственная программа содержит 50 мероприятий. Однако, их название и фактическая реализация не позволяет рассматривать их как адекватную заявленной цели систему мер. Несмотря на наличие в программе приоритетов, она не содержит мероприятий по формированию по каждому приоритету соответствующего промышленного комплекса.

Предусмотренные программой мероприятий, направленные на улучшение финансового состояния организаций промышленности, не финансируются, за исключением предоставления субсидий на возмещение затрат на уплату процентов по кредитам. При этом данное мероприятие финансируется в рамках существующих федеральных мер поддержки [13]. Финансируются только мероприятия, связанные с проведение выставок, ярмарок, конкурсов, премий, организацией и проведением информационной работы, работы по мониторингу деятельности организаций промышленности.

Несоответствие управляющего субъекта и мероприятий Государственной программы заявленной цели не позволяет считать её промышленной политикой (табл. 2).

В Челябинской области меры поддержки в области промышленности осуществляются на основании:

- Закона «О промышленной политике в Челябинской области» [7],

- Подпрограммы «Развитие промышленности Челябинской области на 2016-2018 годы» Государственной программы Челябинской области «Экономическое развитие и инновационная экономика Челябинской области» на 2016-2018 годы (далее - Подпрограмма) [15]".

Цель Подпрограммы сформулирована в общем виде, что не позволяет однозначно сделать вывод о её соответствии объективным тенденциям научно-технологического развития: «создание условий для опережающего развития субъектов деятельности в сфере промышленности Челябинской области как основы повышения ка-

Таблица 2. Характеристика промышленной политики Свердловской области

\begin{tabular}{|c|c|c|c|c|}
\hline \multirow[b]{2}{*}{$\begin{array}{c}\text { Период } \\
\text { времени }\end{array}$} & \multicolumn{3}{|c|}{ Элементы промышленной политики } & \multirow[b]{2}{*}{ Вывод } \\
\hline & Цель & $\begin{array}{c}\text { Управляющий } \\
\text { субъект }\end{array}$ & $\begin{array}{l}\text { Система мер по фор- } \\
\text { мированию промыш- } \\
\text { ленного комплекса }\end{array}$ & \\
\hline $\begin{array}{l}2013 \text { г.- по } \\
\text { настоящее } \\
\text { время }\end{array}$ & $\begin{array}{l}\text { - заявлена; } \\
\text { - соответствует объективным } \\
\text { тенденциям научно-технологи- } \\
\text { ческого развития; } \\
\text { - конкретизирована (приори- } \\
\text { теты определены) }\end{array}$ & $\begin{array}{l}\text { Не соответствует } \\
\text { заявленной цели }\end{array}$ & $\begin{array}{l}\text { Не соответствует } \\
\text { заявленной цели }\end{array}$ & $\begin{array}{l}\text { Промышлен- } \\
\text { ная политика } \\
\text { отсутствует }\end{array}$ \\
\hline
\end{tabular}

* до её принятия действовала Государственная программа Челябинской области «Развитие импортозамещения и научно-производственной кооперации в отраслях промышленности Челябинской области на 2015-2020 годы» [3] 
чества жизни населения». Однако, первая задача Подпрограммы - «создание условий для организации в Челябинской области современных производств по выпуску конкурентоспособной импортозамещающей продукции» - позволяет сделать вывод, что Подпрограмма предусматривает переход к производству продукции не ниже 5-го ТУ. При этом Подпрограмма не содержит приоритетов в виде промышленной продукции и направлений производства.

Управляющий субъект. Принципиальным отличием Подпрограммы Челябинской области является то, что она в качестве управляющего субъекта указывает только государство в лице Министерства экономики и развития и Министерства информационных технологий и связи Челябинской области. В качестве источников её финансирования запланированы только средств областного бюджета - 608,6 млн. руб.

Система мер. С одной стороны, Подпрограмма является не декларативным, а рабочим документом, в качестве мер поддержки промышленности там определены конкретные, подкрепленные источниками финансирования, мероприятия:

1. Субсидии организациям промышленности на возмещение затрат по уплате процентов по кредитам, на возмещение 50\% затрат, связанных с приобретением технологического оборудования и на первоначальный взнос по договору лизинга отечественного оборудования.

2. Создание и финансирование организаций инфраструктуры: Государственного фонда развития промышленности Челябинской области, Центра кластерного развития Челябинской области, интернет-портала «Промышленность».

3. Популяризация рабочих профессий в Челябинской области посредством проведения конкурса «Славим человека труда!».

С другой стороны, содержание данных мер поддержки, условия их предоставления и объе- мы их финансирования не позволяют считать их системой мер по формированию промышленных комплексов:

1. На финансирование первой группы мероприятий на каждый год запланировано 50 млн. руб., но более $50 \%$ данных средств направляется на возмещение затрат на уплату процентов по кредитам, взятым в прошедшие годы (20132016 гг.). Это позволяет сделать вывод о том, что данная мера направлена не на стимулирование будущих инвестиций (не на формирование промышленного комплекса), а на улучшение текущего финансового положения промышленных организаций.

2. На финансирование регионального фона развития промышленности запланировано в год 142 млн.руб., что при предельной сумме льготного займа - 20 млн.руб.- означает поддержку 7-ми проектов. При этом сумма 20 млн. руб. сопоставима с величиной инвестиций небольшого проекта малого или среднего предприятия. Даже годовая сумма средств, выделяемая фонду, недостаточна для формирования промышленного комплекса 5-го ТУ.

Подпрограмма имеет внутреннее противоречие, не позволяющее считать её промышленной политикой: при указании в качестве управляющего субъекта государства, система мер заявленной цели не соответствует: предложенные мероприятия для формирования промышленного комплекса недостаточны (табл. 3).

Анализ трёх региональных промышленных политик: менее промышленно развитой - Курганской области, более промышленно развитых - Свердловской и Челябинской областей, позволяет сделать вывод, об их несоответствии требованиям, предъявляемым к промышленной политике: наличие и непротиворечивость цели, управляющего субъекта и системы мер.

Таким образом, понимание промышленной политики как функции ТУ позволяет понять

Таблица 3. Характеристика промышленной политики Челябинской области

\begin{tabular}{|c|c|c|c|c|}
\hline \multirow[b]{2}{*}{$\begin{array}{l}\text { Период } \\
\text { времени }\end{array}$} & \multicolumn{3}{|c|}{ Элементы промышленной политики } & \multirow[b]{2}{*}{ Вывод } \\
\hline & Цель & $\begin{array}{c}\text { Управляющий } \\
\text { субъект }\end{array}$ & $\begin{array}{c}\text { Система мер по } \\
\text { формированию } \\
\text { промышленного } \\
\text { комплекса }\end{array}$ & \\
\hline $\begin{array}{l}2015 \text { г. - по } \\
\text { настоящее } \\
\text { время }\end{array}$ & $\begin{array}{l}\text { - заявлена; } \\
\text { - соответствует объективным тен- } \\
\text { денциям научно-технологического } \\
\text { развития; } \\
\text { - не конкретизирована (приори- } \\
\text { теты не сформулированы). }\end{array}$ & $\begin{array}{l}\text { Соответствует } \\
\text { заявленной цели }\end{array}$ & $\begin{array}{l}\text { Не соответствует } \\
\text { заявленной цели }\end{array}$ & $\begin{array}{l}\text { Промышлен- } \\
\text { ная политика } \\
\text { отсутствует }\end{array}$ \\
\hline
\end{tabular}


причины низкой результативности реализуемых в регионах России программ по развитию промышленности: ставя в качестве цели переход к производству продукции 5-го или 6-го ТУ, они либо не предусматривают соответствующей системы мер и управляющего субъекта, либо предусматривают реализацию промышленной политики 3-4 ТУ, которая достичь поставленной цели не может. Изменить сложившееся положение дел могло бы внедрение в практику региональных и федеральных органов власти подхода к разработке промышленной политики, предусматривающего четкое установление и непротиворечивость цели, управляющего субъекта и системы мер промышленной политики.

\section{Библиографический список}

1. осударственная программа Курганской области «Развитие промышленного комплекса и повышение его конкурентоспособности на 2014-2018 гг.»: [утв. Постановлением Правительства Курганской области от 14 окт. 2013 г. № 493].

2. Государственная программа Свердловской области «Развитие промышленности и науки на территории Свердловской области до 2020 года»: [утв. Постановлением Правительства свердловской области от 24.10.2013 г. № 1293-ПП]

3. Государственная программа Челябинской области «Развитие импортозамещения и научно-производственной кооперации в отраслях промышленности Челябинской области на 2015-2020 годы»: [утв. постановлением Правительства Челябинской области от 15.09.2015 г. № 439-П]

4. Завадников В.Г. О промышленной политике Российской Федерации. [Электронный ресурс].- Режим доступа: http://federalbook.ru/files/FS/Soderjanie/FS-20/I/Zavadnikov.pdf

5. Закон Курганской области «Об основах промышленной политики Курганской области» № 220: [принят Курганской областной Думой 28 июн. 1999 г.].

6. Закон Свердловской области «Об отдельных вопросах реализации в Свердловской области промышленной политики Российской Федерации» № 136-О3: [принят Законодательным собранием Свердловской обласим 23 нояб. 2015 г.].

7. Закон Челябинской области «О промышленной политике в Челябинской области» № 201-30: [принят 3аконодательным собранием Челябинской области 18 июн. 2015 г.].

8. Карлик А.Е., Комаров А.Г. Промышленная политика, кризис и посткризисное развитие промышленности Санкт-Петербурга // Управленческое консультирование. 2013. № 1, С 77-84.

9. Кобелев В.Н. Промышленная политика как институт адаптивного развития индустриального комплекса региона: автореф. дис... канд. экон. наук: 08.00.05 / Кобелев Виктор Николаевич._- Екатеринбург, 2009. - 25 с.

10. Концепция областной целевой программы «Развитие промышленности Свердловской области и повышение ее конкурентоспособности» на 2014-2018 годы: [утв. Постановлением Правительства Свердловской области от 02.07.2013 N816-ПП].

11. Концепция промышленной политики Курганской области на 2000-2005 гг.: [утв. Постановлением Администрации (Правительства) Курганской области от 04 мая 2000 г. № 257].

12. Концепция промышленной политики Курганской области на 2006-2010 годы: [утв. Постановлением Администрации (Правительства) Курганской области от 22 нояб. 2005 г. № 471].

13. Официальный сайт Министерства промышленности и науки Свердловской области в сети Интернет [Электронный ресурс] - Режим доступа: http://mpr.midural.ru/UPLOAD/user/file/finansirovanie_gos_pr.pdf

14. Официальный сайт Торгово-промышленной палаты Российской Федерации в сети Интернет [Электронный ресурс] - Режим доступа http://www.tpprf.ru/ru/committee/kpr/komprom/analitik.

15. Подпрограмма «Развитие промышленности Челябинской области на 2016-2018 годы» Государственной программы Челябинской области «Экономическое развитие и инновационная экономика Челябинской области» на 2016-2018 годы: [утв. постановлением Правительства Челябинской области от 16.12.2015 г. № 623-П].

16. Потапова Е.Н., Толкачев С.А. Промышленная политика и государственной регулирование экономики (Современные аспекты российской практики) [Электронный ресурс] / Е.Н. Потапова, С.А. Толкачева. Москва. 2006. - Режим доступа: http://www.kapital-rus.ru/articles/article/184742/.

17. Райзберг Б.А., Лозовский Л.Ш., Стародубцева Е.Б. Современный экономический словарь. - 5-е изд., перераб. и доп. Москва. 2007.495 с.

18. Федеральный закон № 488-ФЗ от 31 дек. 2014 «О промышленной политике в Российской Федерации» [принят Гос. Думой 16 дек. 2014 г.]. 
19. Целевая программа Курганской области «Развитие промышленного комплекса Курганской области на 2011-2015 годы»: [утв. Постановлением Правительства Курганской области от 10 авг. 2010 г. № 362].

Поступила в редакцию 09.09.2018 